\title{
Methodological Procedures Applied to the Manufacturing Systems Design
}

\author{
Naqib Daneshjo ${ }^{1}$ \\ 1 Faculty of Business Economics with seat in Kosice, University of Economics in Bratislava, Slovak Republic \\ e-mail: daneshjo47@gmail.com
}

\begin{abstract}
The designing activity has to result in completely new autonomous units sections of complex manufacturing processes and their systems. The solutions must be related to a number of new issues, not only of a technical and technological nature. The solutions designed for new types of interactions between people and technology will be required, and so will be the necessary skills and knowledge. New legal, security, economic, political and ethical solutions to relevant issues will be needed.
\end{abstract}

Keywords: design, multi-level system, CAx systems, innovation

\section{INTRODUCTION}

Designing the manufacturing processes and systems is a complex multi-level system influenced by a large number of factors. Designing requires a deep analysis of targets, ways of preparing and implementing complex and robust manufacturing systems, assessing the impact of important factors, as well as integrating the knowledge of many branches of science and individual divisions. The target of each design is to optimally reduce the design processes while keeping the required quality and minimizing costs. Particularly motivating is the need to focus on eliminating the work-in-progress, improving quality, shortening cycle times, increasing productivity, lowering costs, and so on. Innovations are interpreted as a set of realities that improve the physical, social, intellectual and other structures as well as respect their development, design, implementation and use. The technology-based innovation processes are understood as a complex of social and economic structures depending on the scientific and technological progress, sales requirements and social level of a society.

Higher innovation targets, presented by modern production technologies and production systems, pose high demands on the design preparation. These demands can be satisfied only by adequate development of the design activities and their organization into productive information and knowledge systems ensuring the design quality.

Modern designing has to adapt quickly to the changing requirements for continuous product innovation, manageable variety of variants, meeting unpredictable customer requirements, reduced product lifecycle, responding to significant sales fluctuations, and so on. Preparing the production system for possible changes is no longer economically viable. The main principle of the production systems adaptability is the capability to allow for rapid adaptation of organization and technology at low investment costs.

\section{Production system model and methodological procedures of designing}

Designing modern facilities of mechanical engineering production based on the principles of customer manufacturing is currently affected by development of the market dynamics in all areas. The success of modern engineering production strategies is based on the application of new 
approaches and design methods. It is necessary to solve complex problems of project tasks of which the following is typical $[1,4]$ :

- Scope and multiple options of the engineering and technical solutions.

- High quality of the engineering and technical solutions and their graphical level of informativeness.

- Shortening of the innovative and project cycles.

- Reduction of the development and implementation costs.

The project tasks of designing new production can be successfully managed only by consistently applying the CAx systems throughout the project design solution chain, all the way to their practical implementation. Various modeling techniques and tools as well as optimization and simulation theories are used. The aim is to improve the real concept of the final model before its implementation. In addition to the general project methodologies, special approaches to innovating the CIM-type systems, flexible production, customer-oriented production, etc. are currently under development. From the computer support point of view, the greatest progress has been made in these modern methodological aspects of production design. The basic design strategies are outlined below $[2,3]$ :

- Linear.

- Cyclical.

- Furcated.

- Adaptive.

- Incremental.

- Accidental.

The structure of the production systems includes the technological, handling and control subsystems. They have such a degree of versatility and flexibility and other parameters that result in an internal structure allowing for changing the technological and other functions of the products as required [10].

The production systems can be defined by the potential functions they might have in the implementation of technological processing, handling of object of productions, tools and preparations, and by the information processing functions. At the same time, specific technical subsystems and mutually interacting changes in these subsystems can be defined. As the $V(S)$ models, based strictly on the general theory of systems, often pose problems with interpretation, it is more efficient to start from a narrowed theory of technical systems [2].

The system definition $V(S)$ is based on the theory of technical systems and the system of understanding the production processes. The core positions of the model stem from the solutions published in the original papers. The compositional model $V(S)(1)$ and the system characteristics have been defined with $\mathrm{V}(S)$ ) (2) as follows:

$$
\begin{aligned}
& \mathrm{V}_{(\mathrm{S})}=\mathrm{O}, \mathrm{T}, \Omega \\
& O=\{01, \mathrm{O} 2, . . ., \mathrm{Oa}\} \\
& T=\{T 1, \mathrm{T2}, . ., \mathrm{Tb}\} \\
& \Omega=\left\{\Omega_{1}, \Omega_{2}, . ., \Omega_{c}\right\} \\
& S\left(\mathrm{~V}_{(\mathrm{S})}\right)=\langle\mathrm{C}, \mathrm{F}, \mathrm{S} \\
& C=\{\mathrm{C} 1, \mathrm{C} 2, \mathrm{Cd}\} \\
& F=\{F 1, \mathrm{~F} 2, \mathrm{Fe}\} \\
& \mathrm{Ci}=\{\mathrm{Cis} \mathrm{Cis} \mathrm{Cit}\}
\end{aligned}
$$

where: $O$ - set of operands Oi (object of productions) in $\mathrm{V}_{(\mathrm{S})}$ on which the required transformations are performed (transformation of the semi-finished into a finished product),

$T-$ a set of $T j$ operators executing transformations on operands (active elements of the production system ensuring changes in shape, properties, position, composition, etc.) and activities complementary to these changes (information processing, storage, etc.), $\Omega$ - set of transformation processes $\Omega_{\mathrm{k}}$ running in the $\mathrm{V}_{\mathrm{S})}$-(technological, handling, control and other processes) $C$ - set of targets for which $\mathrm{V}_{(\mathrm{S})}$ is created, $F$ - set of behaviors, or of the manners of functional activity $\mathrm{V}_{(\mathrm{S}) \text {, }}$ $S$ - structure $\mathrm{V}_{(\mathrm{S})}$ expressed by the set of internal links

The system model expressed in formal structures has its own specifics:

1. Provides for a more comprehensive description of the production system elements. It includes describing the outgoing technical means, their interconnections, as well as:

- The object of productions with the relevant attributes. 
- The human factor, in particular as an information base carrier and a controlling element.

- The immediate surroundings of the system acting through inputs and outputs. It highlights the transformative nature of production, not the production system itself, but also its activity, which is in line with the production process patterns.

2. It highlights the objectives of production and the latter's relationship with the wider environment, including the economic and social superstructures of systems.

3. The characteristics of the system behavior are expressed through the operational (manufacturing) procedures.

\section{Interpretation of the system model}

The interpretation options of the system model are documented in Table 1, in which some typical system characteristics are classified.

The system procedure of creating the production systems is illustrated in Figure 1. The system is created in the following four stages:

1. Building a data and knowledge base needed for system creation and detailed analysis of the same.

2. Assembling a virtual model - system structure.

3. Assembling a structural model - detailed project documentation.

4. Implementation in real production premises.

In the model, the sequence of stages or substages of the creation process is symbolically expressed as is the feedback related to fine-tuning and changes to the solution as a gradual reduction of the level of abstraction $[7,8]$.

For the sequence of $V_{(S)}$ creation formulated in this way, the correspondence of the system model $V_{(S)}$ with the internal substages of virtual design $V_{(S)}^{(S)}$ can be expressed as follows:

a) Entities $0_{i} \in V_{(S)}$ and entities $C_{i} \in S\left(V_{(S)}\right)$ correspond to the design stage of goal determination or selecting an object of production. Upon more in-depth analysis, the questions may arise about the internal priority between setting the objectives and selecting the objects of production. In conceptual applications, the starting goals are considered those that are the springboard for modernization of the existing production - the object of production. The system approach operates with dualism of both entities.

b) Entities $\Omega_{j} \in V_{(S)}$ and $F_{j} \in s\left(V_{(S)}\right)$ correspond to the stage of designing operations and operating procedures of manufacturing systems. This aspect is fully compliant with the theory of production processes.

c) Entities $T_{j} \in V_{(S)}$ and $S_{g} \in s\left(V_{(S)}\right)$ correspond to the project activities of selecting production equipment, determining the spatial layout, and so on.

These relationships create a framework according to which various partial design methods $V_{(S)}$ can be integrated into the system concept and, at the same time, they uncover the areas unaccounted for, covered by intuitive procedures in designing $[5,9]$.

The role of the virtual stage of designing is to determine the basic structural elements of the system, their relations and functions, which in empirical methodologies corresponds to the so-called conceptual solution (designing). The structural design stage addresses the detailed system specifications up to the level of project documentation.

The importance of designing target functions in production systems stems from their diversity and the changes required in product manufacturing. The basic structuring of objectives stems

Table 1. Classification of basic system characteristics

\begin{tabular}{|c|c|c|}
\hline Objectives & Structure & Behavior \\
\hline $\begin{array}{l}\text { Social } \\
\text { Reduction of risk } \\
\text { Improvement of quality } \\
\text { Social goals }\end{array}$ & $\begin{array}{l}\text { Robustness } \\
\text { Small } \\
\text { Medium } \\
\text { High } \\
\end{array}$ & $\begin{array}{l}\text { Operands } \\
\text { Sector membership } \\
\text { serial production, production batches } \\
\text { operand properties }\end{array}$ \\
\hline $\begin{array}{l}\text { Economic } \\
\text { Competitiveness } \\
\text { Cost minimization } \\
\text { Investment efficiency }\end{array}$ & $\begin{array}{l}\text { Complexity } \\
\text { Simple (deterministic) } \\
\text { Complex (adaptive) } \\
\text { Intelligent } \\
\end{array}$ & $\begin{array}{l}\text { Operators } \\
\text { Technological, handling, controlling } \\
\text { Technological profile (machining, } \\
\text { assembly, etc.) }\end{array}$ \\
\hline $\begin{array}{l}\text { Technical } \\
\text { Flexibility } \\
\text { Automation } \\
\text { Integration, etc. }\end{array}$ & $\begin{array}{l}\text { Structural level } \\
\text { Module, cell, group } \\
\text { Line, operation, plant }\end{array}$ & $\begin{array}{l}\text { Transformation processes } \\
\text { Operations - methods and structures } \\
\text { Concentration and differentiation }\end{array}$ \\
\hline
\end{tabular}




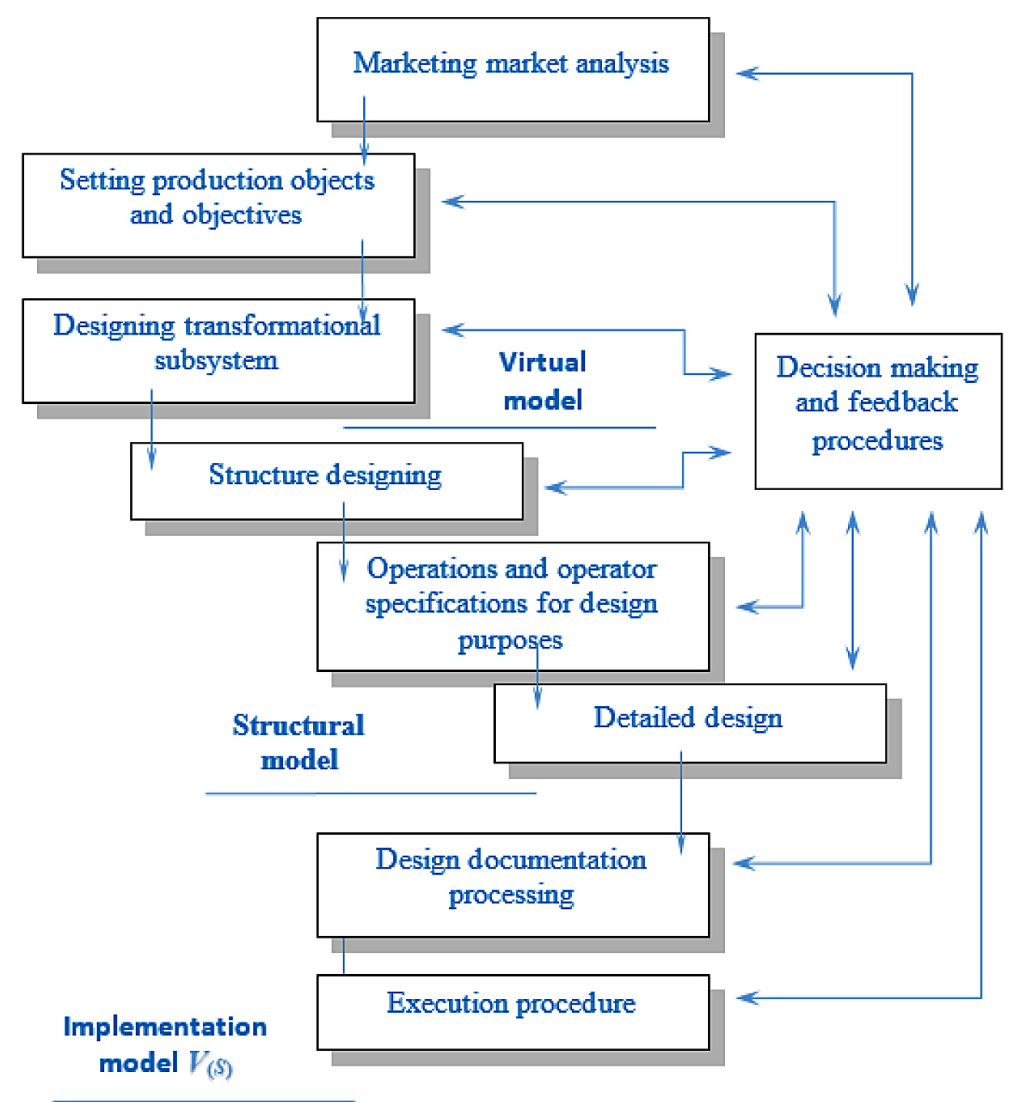

Fig. 1. Methodology of production system creation

from the possibility of integrating the production systems into higher system units. In the hierarchical understanding of the production processes, the systems of greater complexity are superior to the systems of lower complexity. Implementation of superiority in the descending order of social, economic, production and internal goals can be recommended in case of full adoption of new production technologies and their implementation in practice. The priority of social goals can be organized as follows $[2,10]$ :

- Retraining of the workforce.

- Increasing leisure time and choice of working hours.

- Ecological and other aspects.

The social goals linked to an individual are as follows:

- Reducing the risk of accidents and the harmful impact of the working environment on human health.

- Reducing the intensity of the physical and mental work.

- Reducing the monotony and the amount of unattractive work.

- Reducing the discomfort of the working environment, and so on.
For general development of social orientation of production, it is important that the priority of the social goals and their quantitative assessment are not impaired in the stage of project preparation. In the context of systematization of economic objectives, in line with the current understanding of efficiency, the following priority should be accepted $[2,11]$ :

- Adding the product value necessitated by the increasing competition on the global market. This is achieved by shortening the innovative creation cycles and starting up new products, using new knowledge, customizing the product to customer requirements through its modifications, short delivery times, and so on.

- Reduction of the production costs. In addition to the generally practiced labor cost reduction, the material, energy and information costs need to be reduced, too. Contradictions should be eliminated to a certain extent by introducing modern systems with higher economic efficiency of production.

- Investment cost optimization. Optimizing this goal is essential because each manufacturer is limited by the investment resources at their disposal. 
The analyses of targets at the level of production systems are currently well outlined in terms of both scientific knowledge and design practice. Definition of production goals such as producibility, production process continuity, stability, reliability, quality, etc. is known from the theory of the production processes, and - with some modifications - they can be applied to the customeroriented production. The basic structure of production goals in designing production systems is shown in Figure 2

More significant differences in technical objectives $V_{(S)}$ may be caused during the process of determining the level of flexibility and automation. The priority of elasticity $V_{(S)}$ arises from its relation to the competitiveness of the production demonstrated by manufacturing products according to the customers' requirements.

In order to comply with the mentioned system's model, the $V_{(S)}$ flexibility needs to be defined as a target characteristic, which expresses the possibility of performing the desired transformations on a wide range of operands, changing the range of operands and transformations.

In terms of quality, flexibility may be evaluated as a number of the operand variants and their transformations and the degree of the necessary influence (interference) from the environment to facilitate the transition from one variant to another. Detailed methodological procedures for the flexibility assessment were elaborated in several papers of the parent workplace. The flexibility of a condition may be interpreted by the ability of $V_{(S)}$ to change the production tasks by changing the technical operator parameters, programs, and so on.
Structural flexibility $V_{(S)}$ is related to the evolution of the system through the qualitative differentiation of functional operator capabilities and their interactions with new ones. It can be interpreted as the ability to reconfigure the system while retaining its essence. The degree of difficulty with which the environment intervenes in the condition or the $V_{(S)}$ structure upon the change in the range of operands can be evaluated as follows:

- By means of the time it takes to move on to a new production task.

- By the cost of reconfiguring the system.

The constraints of the manufacturing process are specified in the following groups:

- Objects of production.

- Technologies applied.

- Surroundings.

The analysis of the constraints affecting the objects of manufacturing can be based on a progressive evaluation of the selection function:

$$
R\left(b_{i}\right)={ }_{1}^{0}\left\{=\left\{b_{1}, b_{2}, \ldots, b_{n}\right\},\right.
$$

where: $R$-decisive selection function, $b i$ - i-th constraint of $\mathrm{V}(\mathrm{S})$, $R(b i)=0-\mathrm{V}(\mathrm{S})$ lacks the assumption of meeting the bi constraint,

$R(b i)=1-\mathrm{V}(\mathrm{S})$ is assumed to meet the bi constraint,

$n$ - number of constraints considered.

It holds that the objects of production are suitable for $V_{(S)}$ if each $\mathrm{R}(\mathrm{bi})=1$ when $i=1, \ldots n$. In practice, it is expedient to arrange the sets of

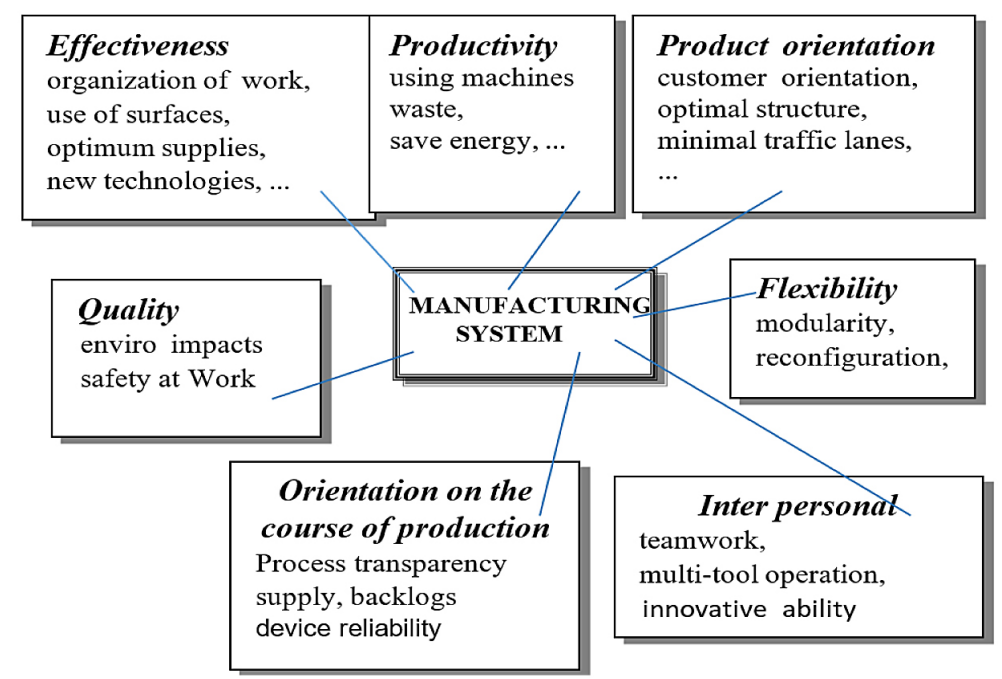

Fig. 2. Structure of production goals in the production systems design 
constraints in such manner that the lower index restrictions have greater negative value $R\left({ }_{b i}\right)$ probability. The objects of production pose most frequent constraints.

The concept of the stated system allows for the incorporation and use of the previously developed design methodologies and procedures. The following activities are important for production $[2,12]$ :

- Profiling activities focused on the objects of production, production processes and production system structures.

- Methods and techniques for creating and optimizing the methods and structures of manufacturing operations.

- Methods and techniques for the synthesis of production systems - general method structures, construction and modernization models, interface solutions, spatial problems solutions, material and information flows, etc..

- Implementation procedures and knowledge from experimental activities, following the theoretical and knowledge base of the area under study.

Production workstations, systems and clusters are made up of a number of building elements and units of technological processing, operational and inter-operational handling and storage, control, interconnection, and the like. At the same time, production workstations, systems and clusters generally include the production units capable of executing a coherent part of the production process.

Production systems can be grouped into more complex units (production department, operation, plant). Production systems can be grouped into higher aggregates only if the principle that the number of their mutual relations is greater than the number of relations of such a whole, is applicable. The theory of clustering building elements and units of manufacturing workstations and systems leans on the principle of recurrent development elaborated in systemology. The base level structure is homogeneous and is defined as an element. The next higher unit is made up of this element plus another element of the same or new quality. Thus, a complex, multi-level system can be gradually built this way.

In production systems, elements are represented by the manufacturing technology. In production systems, the elements represent the manufacturing equipment, replaced in the description by the character models depicting real-time functions situated in space. Moreover, these functions can

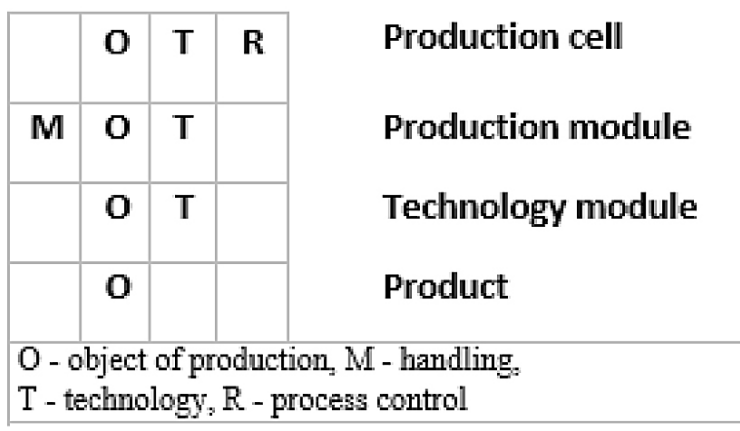

Fig. 3. Principle of recurrent generation of production systems

be algorithmized and they give rise to organizational links. Figure 3 illustrates the application of the recurrent principle in the production systems.

Structural construction starts from an object of production having the primary position. It can be defined as an individual object or a group of objects clustered according to certain rules (group technology). By adding technological features, represented by the machine-preparation-tool system, the opportunity to carry out the technological process is created.

Another level is created by adding the handling functions. A material model may be represented by a machine-robot-product system, or a self-service machine the product. Another level in this hierarchy is achieved by adding the control functions to the technological processing and handling system.

\section{Uses new methodological procedures and activity algorithms}

In this way, a production module can be created as a system having the structure and parameters of technological, handling and control compatibility. It allows for the creation of the production systems with their own structure and parameters. An important aspect, however, is the system compatibility of the technological, handling and control devices. The construction model shape is that of a pyramid (Fig. 4). The design of production workstations, systems and clusters, taking into account specific technical, organizational and economic conditions, uses new methodological procedures and activity algorithms. In this process, valid regulations and classical design legislation must be adhered to, there are certain specific conditions, different methodological and algorithmic procedures. 
From the content point of view, when designing manufacturing workstations, systems and clusters, it is necessary to ensure the processing of a set of functions according to their technical specifications.

These functions can be structured into the type modules of project activity - see Figure 5 . The custom methodology for designing production systems requires the following development techniques:

- Developing the project model.

- Setting the project objectives.

- Creating a conceptual design.

- Detailed design.

- Creating a project implementation plan.

- Solution implementation.

Standardization is therefore expected to overcome a number of problems with the design, implementation and operation of production systems and clusters. Particularly significant ones include:

- Narrowing the choice of possible solution variants.

- Achieving a higher degree of optimization due to application of already known solutions.
- Ensuring a higher level of unification and stabilization.

- Ensuring uniform project procedures.

- Developing modularity in the building process and modularity in project solutions.

- Creating preconditions for development of the automation of project procedures, and so on.

Design types of production workstations, systems and clusters are also a significant reference solution that is applicable to the given manufacturing conditions, bringing the benefits of eliminating the design shortcomings, in particular in terms of cost, time of preparation and implementation or in terms of competitiveness. In the design and development of production workstations, systems and cluster design types, it is essential that the advanced design methods be applied. Currently, the crucial part is the computer support, i.e. the use of advanced programming and information systems. The development and use of professionally-focused application programming and information systems must be closely linked to the progress made in the standardization of advanced graphical systems.

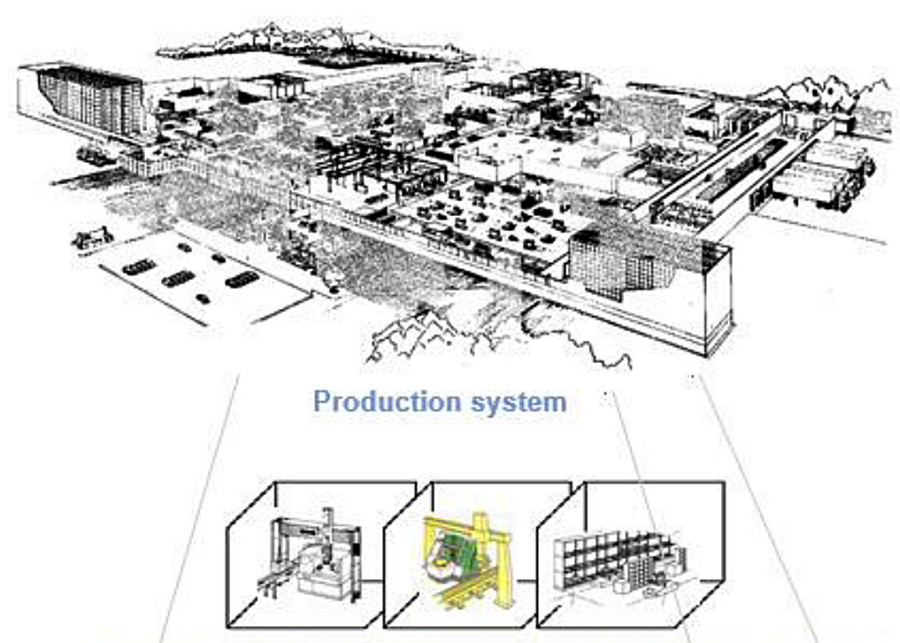

Technological, handling, control and auxiliary subsystems
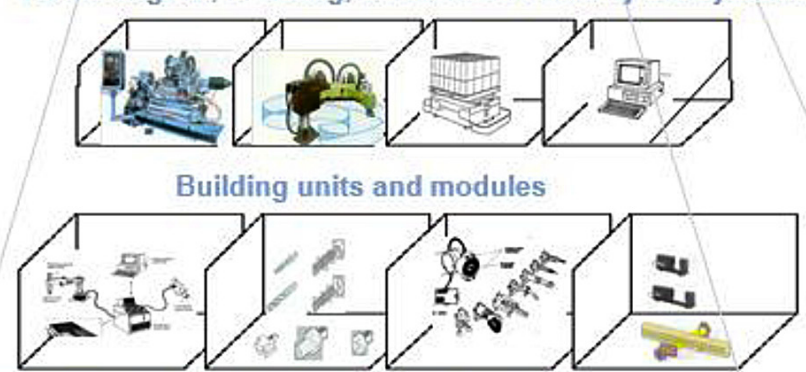

Elemental and nodal base - technological components

Fig. 4. Pyramidal structure of the production system creation 


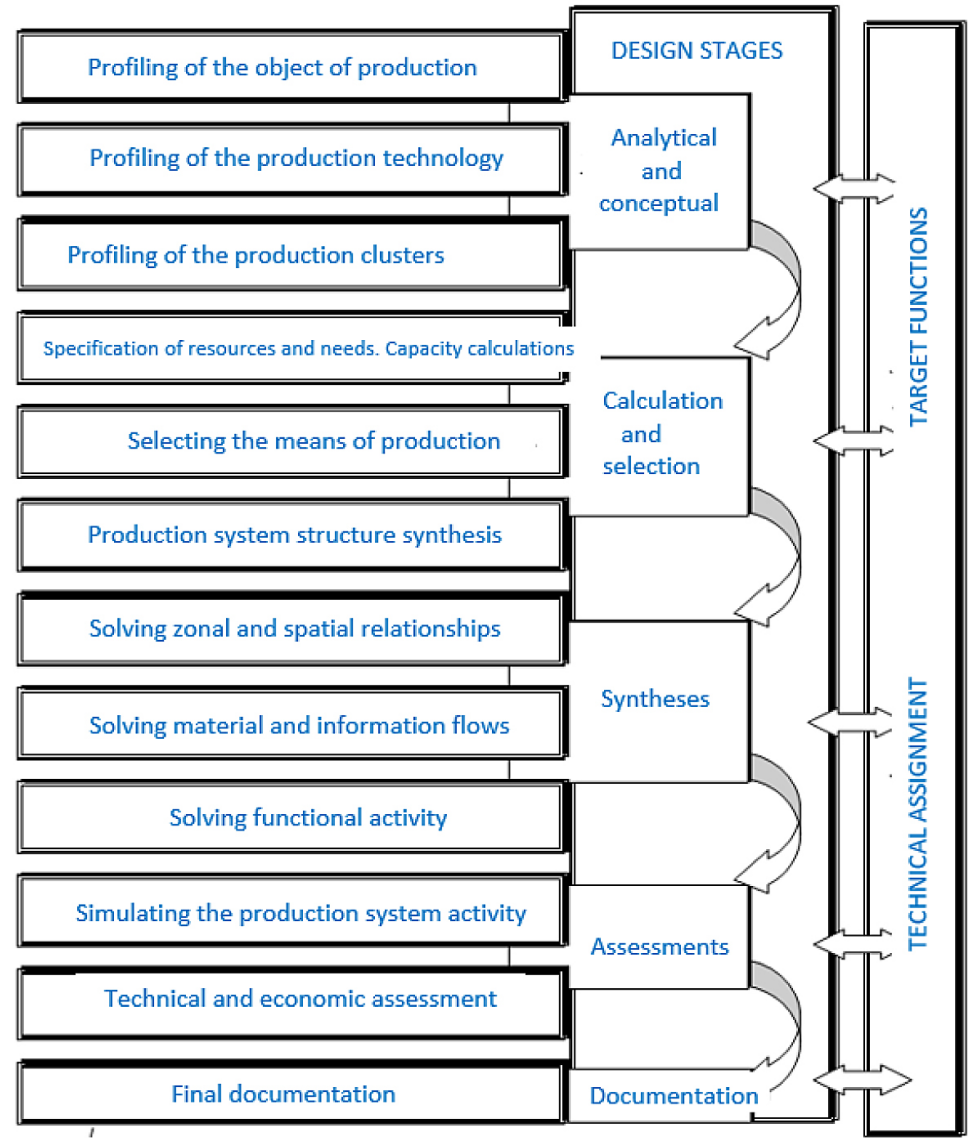

Fig. 5. Main types of activities in production system designing

In addition, the principles of modular construction should be fully accepted in the methodological procedures of designing type-specific production workstations and systems. This is a highly effective development tool supported by several aspects. The main ones appear to be:

- Design (proposal), enabling the computer optimization of the variants of the solution of professional tasks due to unification of methodological procedures in modular construction and its own preparation;

- Production-application, reducing the cost of developing application programs and increasing efficiency owing to wider implementation possibilities;

- Operational, leading to lower operating costs, modification and focus of application programs.

The type-specific production workstations, systems and cluster designs must be expressed in the design documentation in such a way as to ensure the technical feasibility of their implementation under the given conditions. Therefore, it is necessary to consider the clarity of the solution and its information completeness as an important factor in the design of the project documentation.

It is also necessary to take into account the relevant legislative constraints in the design methodologies as well as in the project documentation.

The philosophy of innovative, varied, and interactive designing is based on the assumption that the production system solution takes place in three stages:

- An initial set of variants of the production system solution is proposed in accordance with the agreed objectives. Various methods for determining the solution variants (analytical, morphological, hierarchical generation, use of reference solutions, etc.) can be used. For less complex tasks, intuitive ways of variant generation, based on the reference type-specific patterns, can be used.

- Feasible solutions are defined. Inappropriate variants of the production system solution are excluded, either based on the intuitive or logical and mathematical methods.

- The optimal variant of the production system solution is chosen in the final stage. The decision-making methods, or optimization 


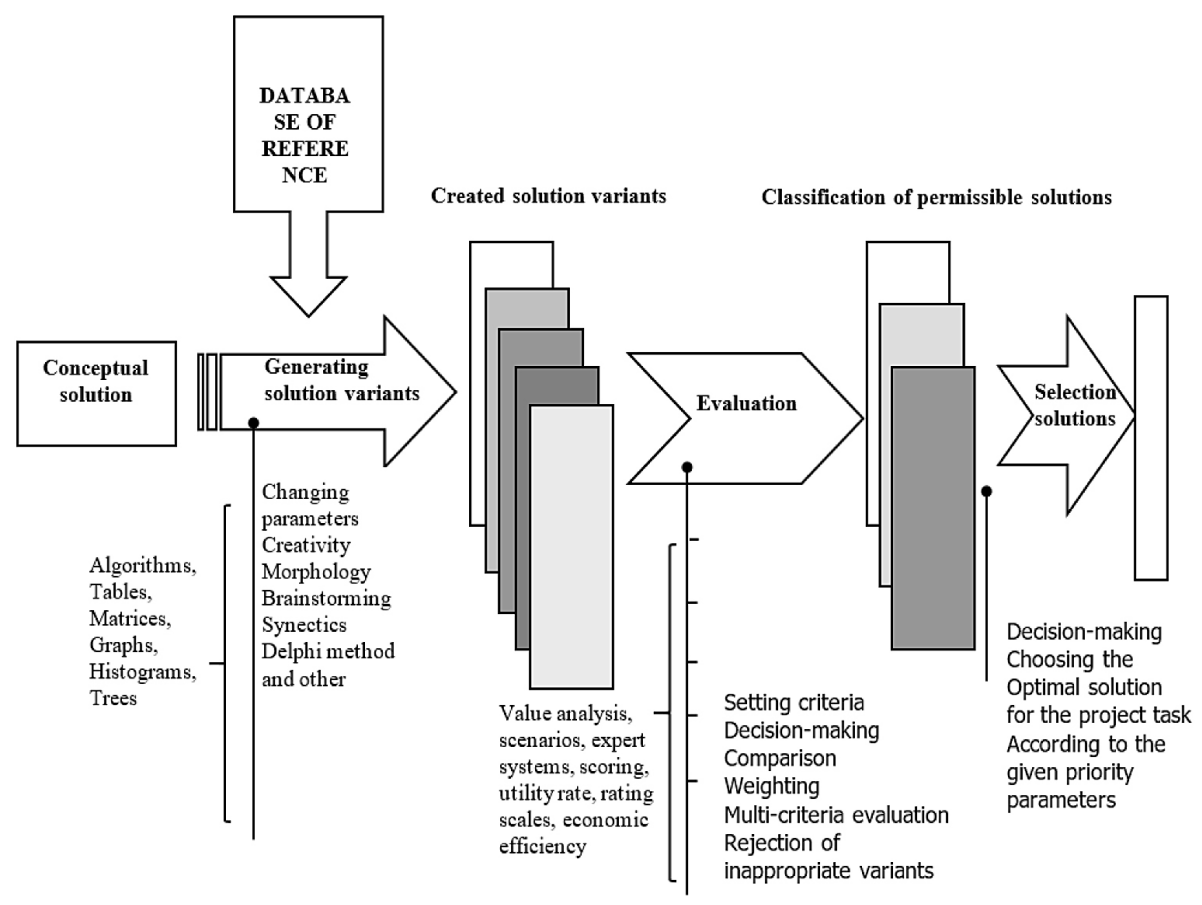

Fig. 6. Principle of Variant Designing of Production Systems

criteria are applied. The optimal variant can be obtained as a result of comparative methods (reference projects), based on the simulation activity, etc.

The principle of variant designing of production systems is shown in Figure 6.

The choice of an optimal concept for the solution of the spatial structure of the production system is proposed based on the application of the methodological methods of production segmentation. Segmentation is a form of application of group principles to production, and in particular, it enables the execution of progressive cellular structures of the production systems. Segmentation can be accomplished in two basic ways:

- Vertically, vertical segmentation is based on individual types of the products manufactured.

- Horizontal way is to form segments horizontally within the vertical segments, i.e. the number of steps in the production process is reduced and so is the product complexity.

\section{CONCLUSION}

Designing the manufacturing processes and systems is a complex multi-level system influenced by a large number of factors. Designing requires a deep analysis of targets, ways of preparing and implementing complex and robust manufacturing systems, assessing the impact of important factors, and integrating the knowledge of many branches of science and individual divisions. The target of each design is to optimally reduce the design processes while keeping the required quality and minimizing costs. Particularly motivating is the need to focus on eliminating the work-in-progress, improving quality, shortening cycle times, increasing productivity, lowering costs, and so on. Innovations are interpreted as a set of realities that improve the physical, social, intellectual and other structures as well as respect their development, design, implementation and use. The technology-based innovation processes are understood as a complex of social and economic structures depending on scientific and technological progress, sales requirements and social level of a society.

Higher innovation targets, presented by modern production technologies and production systems, pose high demands on design preparation. These demands can be satisfied only by the adequate development of the design activities as well as their organization into the productive information and knowledge systems ensuring the required design quality.

Modern designing has to adapt quickly to the changing requirements for continuous product innovation, manageable variety of variants, meeting unpredictable customer requirements, reduced product lifecycle, responding to significant sales 
fluctuations, and so on. Preparing the production system for the possible changes is no longer economically viable. The main principle of the production systems adaptability is the capability to allow for rapid adaptation of an organization and technology at low investment costs.

\section{Acknowledgement}

This work has been supported by the Scientific Grant Agency of the Ministry of Education of the Slovak Republic (KEGA 026EU-4/2018 and KEGA 032EU-4/2020)

\section{REFERENCES}

1. Daneshjo N., Mareš A., Dudáš Pajerká E. Solving the spatial relationships in manufacturing systems. Advances in Science and Technology: Research Journal, 14(2), 2020, 120-130.

2. Daneshjo, N., Rudy, V., Repková, K., Mareš, A., Kováč, J., Jahnátek, J., Krivosudská, J., Šmajda, N., Rusnák, J.: Intelligent industrial engineering - Innovation potential. FedEx Print \& Ship Center, USA, 2018.

3. Daneshjo, N., Majernik, M., Dudaš Pajerská, E. Danishjoo, M.: Methodological Aspects of Modelling and Simulation of Robotized Workstations. TEM Journal, 2, 2018, 293-300.

4. Daneshjo N., Malega P.: Changing of the maintenance system in the production plant with the application of predictive maintenance. TEM Journal,
9(2), 2020, 434-441.

5. Fabian, M., Boslai, R., Ižol, P., Janeková, J., Fabianová, J., Fedorko, G., Božek, P.: Use of Parametric 3D Modelling - Tying Parameter Values to Spreadsheets at Designing Molds for Plastic Injection. Manufacturing Technology, 15, 2015, 24-31.

6. Kovač J., Rudy V., Kováč J.: Methods for the design of production processes. Specifics of designing production systems. Edition of professional and scientific literature. TU UK Košice, 2017, p. 326.

7. Plinta D., Krajcovic.: Production system designing with the use of digital factory and augmented reality Technologies. Advances in Intelligent Systems and Computing, 350, 2016, 187-196.

8. Buckova M., Krajcovic M., Edl M.: Computer simulation and optimization of transport distances of order picking processes.12th Internacional scientific conference of young scientists on sustainable, modern and safe transport Book Series: Procedia Engineering, 192, 2017, 69-74.

9. Hammer M., The Superefficient Company. Harvard Business Review, 79(9), 2001, p. 84.

10. Monczka R.M. and Morgan J., What's Wrong with Supply Chain Management? Purchasing, 122(1), 1997, 69-72.

11. Lambert D.M., Cooper M.C. and Pagh J.D., Supply Chain Management: Implementation Issues and Research Opportunities. The International Journal of Logistics Management, 9(2), 1998, p. 1.

12. Lambert D.M. and Pohlen T.L., Supply Chain Metrics. The International Journal of Logistics Management, 12(1), 2001, 1-19. 